Mean age (SEM) was 41.1 (1). There was an $8.5 \%$ difference in FEV1\% between groups A and C, (95\% CI (2.6\% to $14.4 \%) \mathrm{p}=0.002)$ and a $29 \%$ difference for $\mathrm{FE}_{\mathrm{NO}}$ between groups $\mathrm{A}$ and $\mathrm{C},(95 \% \mathrm{CI}(2 \%$ to $48 \%) \mathrm{p}=0.034)$. There was a 1.29 doubling dilution difference in methacholine $\mathrm{PC}_{20}(95 \% \mathrm{CI}$ ( 0.26 to 2.33$\left.) \mathrm{p}=0.009\right)$ between groups $\mathrm{D}$ and $\mathrm{F}$. There was no significant difference between FEV1\% when grouped by $\mathrm{FE}_{\mathrm{NO}}$ (See Abstract P25 Table 1). Applying multiple stepwise linear regression showed that $\mathrm{FE}_{\mathrm{NO}}$ and $\mathrm{FEV} 1 \%$ were both significant predictors of methacholine PC20 ( $p=0.002, p<0.001)$. Only methacholine $\mathrm{PC}_{20}$ was a significant predictor of $\mathrm{FE}_{\mathrm{NO}}$ $(\mathrm{p}=0.002)$.

Abstract P25 Table 1 FEV1 are Arithmetic Means and $95 \% \mathrm{Cl}$ and skin prick Median and IQR. Methacholine $\mathrm{PC}_{20}$ are Geometric Mean and $95 \% \mathrm{Cl}$

\begin{tabular}{|c|c|c|c|}
\hline \multirow[b]{2}{*}{ Outcome } & \multicolumn{3}{|c|}{ Methacholine $\mathbf{P C}_{20}(\mathrm{mg} / \mathrm{ml})$} \\
\hline & $\begin{array}{l}\text { Group A } \\
\mathrm{n}=82 \\
\leq 0.5\end{array}$ & $\begin{array}{l}\text { Group B } \\
n=60 \\
>0.5-2\end{array}$ & $\begin{array}{l}\text { Group C } \\
n=66 \\
>2-8\end{array}$ \\
\hline FEV $1 \%$ & $86.5(82.9-90.1)^{*}$ & $90.4(87.4-93.5)$ & $95.0(91.4-98.7)^{*}$ \\
\hline FENO & $28.1(23.4-33.8)^{*}$ & $30.6(24.9-37.6)$ & $39.3(32.8-47.0)^{*}$ \\
\hline No. + ve Skin Pricks & $3(2-5)$ & $3(2-5)$ & $3(1-4)$ \\
\hline$\%$ on ICS & $53 \%$ & $51 \%$ & $39 \%$ \\
\hline Median BDP dose (ug) & 400 & 400 & 400 \\
\hline \multirow[t]{3}{*}{ Outcome } & \multicolumn{3}{|c|}{ Exhaled Nitric Oxide (FENO) (ppb) } \\
\hline & Group D $\mathrm{n}=79$ & Group $\mathrm{E} n=72$ & Group $\mathrm{F} \mathrm{n}=57$ \\
\hline & $\leq 25$ & $>25-50$ & $>50$ \\
\hline FEV $1 \%$ & $89.9(86.7-93.1)$ & $91.5(87.8-95.3)$ & $88.9(85.0-92.9)$ \\
\hline Methacholine PC20 & $0.99(0.67-1.47)^{*}$ & $0.59(0.39-0.89)$ & $0.41(0.26-0.63)^{*}$ \\
\hline No. + ve skin pricks & $3(2-4)$ & $3(2-4)$ & $3(2-5)$ \\
\hline$\%$ on ICS & $41 \%$ & $44 \%$ & $33 \%$ \\
\hline Median BDP dose $(\mu \mathrm{g})$ & 400 & 400 & 400 \\
\hline
\end{tabular}

*Significant difference between groups $A$ versus $C$ or between $D$ versus $F p<0.05$.

Conclusion Our study has highlighted the disconnect between airway inflammation and airway calibre, whilst showing a significant relationship between AHR versus airway calibre and inflammation. Thus, whilst relationships exist between these independent outcomes, the lack of complete concordance highlights the important role that each contributes to the assessment of the asthmatic individual.

\section{P26 HOME SERIAL SPIROMETRY AS AN ADJUNCT IN THE DIAGNOSIS OF VOCAL CORD DYSFUNCTION}

doi:10.1136/thx.2010.150961.26

S Y Barnett, B Ziso, S J Quantrill. Whipps Cross University Hospital NHS Trust, London, $U K$

Introduction The diagnosis of vocal cord dysfunction (VCD) is often difficult. Visualisation of the vocal cords using laryngoscopy is the current gold standard method of diagnosis, but may not be diagnostic if carried out when the patient is asymptomatic. An inspiratory flow volume manoeuvre performed during spirometry aids diagnosis, indicating inspiratory flow obstruction when flattened, but is subject to the same problem. Home serial spirometry (HSS), however, may improve diagnostic yield as it can be performed on demand, when the patient experiences symptoms.

Methods A retrospective review was performed of all patients referred to a District General Hospital with symptoms suggestive of VCD, between May 2005 and July 2010. Static spirometry was performed by a lung physiologist within the department. Patients were educated to perform HSS using a Jaeger Spiropro ${ }^{\circledR}+$ handheld spirometer immediately on experiencing symptoms. Results were downloaded when the machine was returned after a 2-week period. Direct visualisation of the vocal cords via laryngoscopy was performed by a respiratory physician.

Results 54 patients were investigated for possible VCD. A final diagnosis of VCD was made in $31(57 \%)$ cases. Inspiratory loop flattening on static spirometry was present in $48 / 54$ (88\%) patients investigated and 28/31 (90\%) confirmed cases of VCD. There was evidence of inspiratory loop flattening on HSS in $28 / 39$ (71.7\%) patients. $22 / 39$ (56\%) who had laryngoscopy were found to have evidence of VCD. 25 patients had both laryngoscopy and HSS performed: 14 of these had evidence of VCD on both tests. 3 of the positive laryngoscopy results were associated with normal HSS There were eight cases with flattened inspiratory loops on HSS in patients in whom no abnormality was found on laryngoscopy. Conclusion The nature of laryngoscopy, necessarily performed at one point in time, limits its value in the diagnosis of VCD. HSS is a useful non-invasive test that can increase diagnostic yield in VCD.

\section{P27 PERSONAL ALLERGEN EXPOSURES ARE INCREASED BY CHANGES IN SLEEP POSITION AND IMPROVED BY TEMPERATURE-CONTROLLED LAMINAR AIRFLOW}

doi:10.1136/thx.2010.150961.27

${ }^{1} \mathrm{RB}$ Gore, ${ }^{2} \mathrm{RJ}$ Boyle, ${ }^{2} \mathrm{H}$ Hanna, ${ }^{1} \mathrm{~A}$ Custovic, ${ }^{2} \mathrm{C}$ Gore, ${ }^{3} \mathrm{P}$ Svensson, ${ }^{2} \mathrm{~J} 0$ Warner. ${ }^{1}$ University of Manchester, Manchester, UK; ${ }^{2}$ Imperial College, London, UK; ${ }^{3}$ Airsonett $A B$, Angelholm, Sweden

Introduction and Objectives Aeroallergens are released directly from bedding into the breathing zone, and contribute importantly to asthma symptoms. Adults change their sleep position between 3 and 45 times per night. The effect of these turns on inhaled particulate exposures is unknown. We aimed to investigate the effects of changing position on breathing zone particulate exposures and the effect of a novel Temperature-controlled Laminar Airflow (TLA) device on reducing such exposures.

Methods A simulated bedroom was constructed containing bedding from a cat owner. Five healthy volunteers lay recumbent under an active and an inactive TLA device for $175 \mathrm{~min}$. Volunteers made scheduled turns in bed to simulate normal sleep. Real-time total

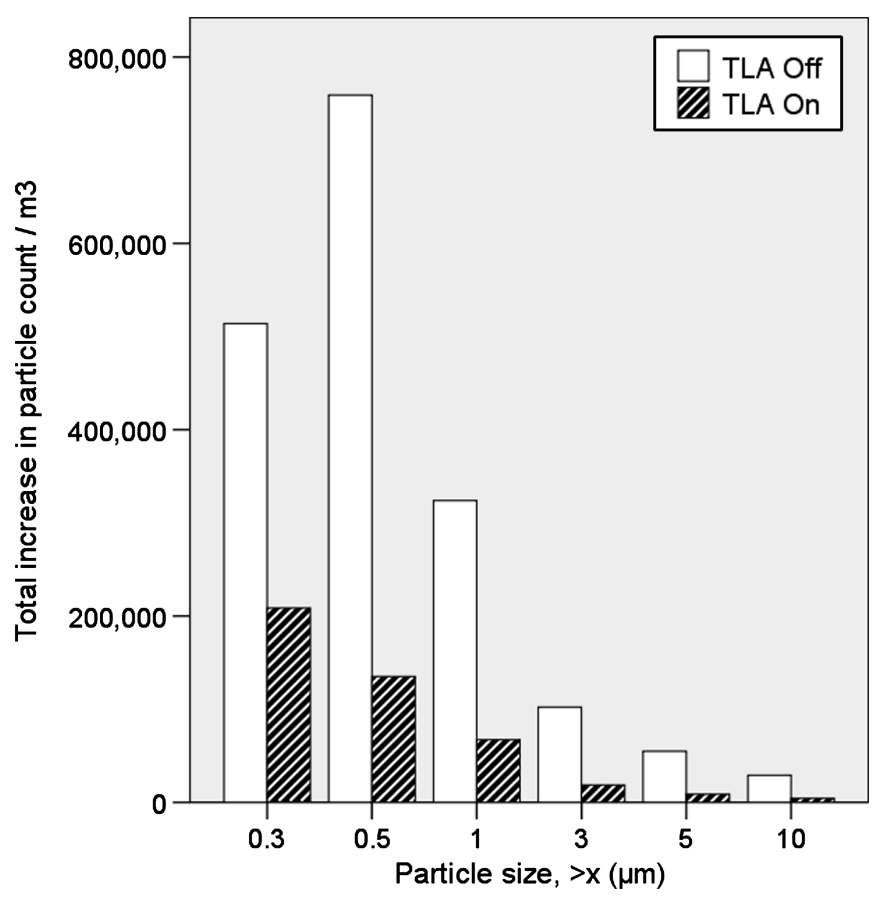

Abstract P27 Figure 1 